\title{
KNOWLEDGE, ATTITUDE AND PREVENTIVE PRACTICES REGARDING HYPERTENSION AMONG 40 YEARS AND ABOVE POPULATION RESIDING IN MAHADEVSTHAN, KATHMANDU
}

Khatri $\mathrm{E}^{1,2 \dagger}$, Marahatta $\mathrm{SB}^{3}$, Yadav $\mathrm{RK}^{4,2}$, Devkota $\mathrm{N}^{5}$

${ }^{1}$ Patan Academy of Health Sciences

${ }^{2}$ Health Research Together (HeaRT)-Initiative

${ }^{3}$ Manmoham Memorial Institute of Health Sciences

${ }^{4}$ School of Health and Allied Sciences, Pokhara University

${ }^{5}$ Central Institute of science and Technology, Pokhara University

${ }^{\dagger}$ Corresponding Author: Elina Khatri Patan Academy of Health Sciences

Email: elinakhatri1992@gmail.com

\section{ABSTRACT}

Background: Hypertension is a leading cause of cardiovascular diseases in both developed and developing countries. In recent time the epidemiological transition of countries from communicable diseases to non-communicable diseases had increased its importance. Hypertension had been ranked as a top five cause of mortality in Nepal. Assessment of knowledge, attitudes, and practices (KAP) is a crucial element of hypertension control, but little information is available from developing countries where hypertension has lately been recognized as a major health problem.

Objectives: To assess knowledge level, attitude and preventive practices regarding hypertension among 40 years and above population residing in Mahadevsthan, Kathmandu.

Methodology: A cross sectional analytical study was conducted using Probability Proportionate Sampling (PPS) in 9 wards of Mahadevsthan, Kathmandu. Interview was done with closed ended Questionnaire for data collection among 165 respondents aged 40 years and above.

Results: The study shows that the distribution of hypertension among respondents to be $22.4 \%$. The mean age of respondents was 55 years with maximum of 97 years. The average knowledge score was 12.9 out of total 41 score. More than half of respondents i.e. 52.1\% had a good knowledge on hypertension.

Keywords : Attitude; Hypertension; Knowledge; Practices; Mahadevsthan VDC 


\section{INTRODUCTION}

Hypertension is one of the most crucial health problems and also the most common chronic disease in both developed and developing countries ${ }^{(1)}$. Hypertension has become a significant problem in many developing countries experiencing epidemiological transition from communicable to noncommunicable chronic disease ${ }^{(2)}$. It is known as the silent killer disease which is diagnosed incidentally. Hypertension is a preventable and treatable condition but if not treated on time leads to serious life threatening complications such as heart, brain and renal disorders which in most cases results in disability ${ }^{(1)}$.

Globally, 7 million people die every year because of hypertension ${ }^{(3)}$. Hypertension is the leading risk factor for mortality worldwide, contributing to $13 \%$ of all deaths. It is estimated that $62 \%$ of cerebrovascular disease and $49 \%$ of ischemic heart diseases are contributed by high blood pressure $^{(4)}$.The assessment of knowledge, attitudes, and practices (KAP) of hypertension is a crucial element for its control, but very little information is available on developing countries like Nepal where hypertension has lately been recognized as a major health problem ${ }^{(5)}$.

\section{Objectives:}

The primary objective of the paper was to study knowledge, attitude and practices regarding Hypertension among 40 years and above residing in Mahadevsthan VDC. However, the specific objectives were to determine the level of knowledge regarding, attitude and preventive practices among participants for hypertension.

\section{Methods and materials:}

The study design was cross sectional analytical done by using a questionnaire to get their level of knowledge, attitudes and practices regarding hypertension among 40 years and above permanent residents of Mahadevsthan VDC, Kathmandu. The study population was chosen as such as world prevalence of hypertension has shown high prevalence among older adults (50 years and above).

The sampling design was Probability proportionate sampling (PPS). It was done in two stages where in first step sampling was done proportionately among wards after that the proportion of participants were taken simple randomly based on the sampling frame (voters list) obtained from 
the village development committee office. The study was almost four months starting from September to December 2014.

After the completion of data collection, it was reviewed, organized and entered into epi data software to validate and analyze the entries in SPSS 20. Validity was maintained by continued review of the available literatures and consultation with experts. For the data reliability, 10\% of the sample population was taken for pretesting in Thankot VDC. Also, researcher was directly engaged in data collection, cross-checking, data entry, processing and analysis so as to maintain consistency.

\section{Limitations of the study}

The sample size might not be sufficient enough to generalize the findings to all the older adults of Kathmandu district. The factors associated with the knowledge, attitudes and practices regarding hypertension were not explored in detail by this study.

\section{Ethical Consideration}

The ethical consideration for the conduction of research was taken from Nepal Health Research Council. A verbal consent was taken from study participants prior to data collection by explaining the purpose and objectives of study. The privacy and confidentiality of the information was maintained.

\section{RESULTS}

This study shows that the majority of the respondents comprised of age group 40-49 (34.5\%) followed by age group 50-59 (32.1\%). The study covered 97 (58.8\%) male and 68 (42.2\%) female respondents. The majority of respondents i.e. 158 (95.8\%) were Hindu. Among these respondents 24.2\% were illiterate, $32.1 \%$ can read \& write.

Table 1: Socio-demographic characteristics of respondents

\begin{tabular}{lll}
\hline Variable & Frequency $(\mathbf{n}=165)$ & Percent \\
\hline Age group & & \\
$40-49$ & 57 & 34.5 \\
$50-59$ & 53 & 32.1 \\
$60-69$ & 33 & 20 \\
$70-79$ & 18 & 11 \\
\hline
\end{tabular}




\begin{tabular}{lll}
\hline $80-89$ & 2 & 1.2 \\
$90-99$ & 2 & 1.2 \\
Sex & & \\
Male & 97 & 58.8 \\
Female & 68 & 41.2 \\
Religion & & \\
Hindu & 158 & 95.8 \\
Buddhist & 1 & 0.6 \\
Christian & 6 & 3.6 \\
Ethnicity & & \\
Brahmin & 22 & 13.3 \\
Chettri & 51 & 31 \\
Janajati & 77 & 46.7 \\
Dalit & 10 & 6 \\
Others & 5 & 3 \\
Education & & \\
Illiterate & 40 & 24.2 \\
Can read and write & 53 & 32.1 \\
Primary level & 14 & 8.5 \\
Secondary level & 40 & 24.2 \\
Higher education & 18 & 11 \\
\hline
\end{tabular}

The above study shows that the majority of the respondents comprised of age group 40-49 (34.5\%) followed by age group 50-59 (32.1\%). The study covered 97 (58.8\%) male and 68 (42.2\%) female respondents. The majority of respondents i.e. 158 (95.8\%) were Hindu. Among these respondents $24.2 \%$ were illiterate, $32.1 \%$ can read $\&$ write.

Knowledge on Hypertension

Table 2: Knowledge on Hypertension

\begin{tabular}{lll}
\hline Definition of HTN & No of respondents $(\mathbf{n}=\mathbf{1 6 5})$ & Percent \\
\hline Elevated blood pressure & 89 & 54 \\
Rise in systolic blood pressure & 6 & 3.6 \\
Rise in diastolic blood pressure & 1 & 0.6 \\
Don't know & 69 & 41.8 \\
\hline Normal range of BP & No of respondents $(\mathbf{n}=\mathbf{1 6 5})$ & Percent \\
\hline
\end{tabular}




\begin{tabular}{|c|c|c|}
\hline Don't know & 102 & 61.8 \\
\hline 110/80 mm Hg & 2 & 1.2 \\
\hline 120/80 mm Hg & 56 & 34 \\
\hline 130/90 mm Hg & 5 & 3 \\
\hline Symptoms & No of respondents $(n=165)$ & Percent \\
\hline Severe Headache & 67 & 40.6 \\
\hline Drowsiness or confusion & 85 & 51.5 \\
\hline Vision problems & 10 & 6 \\
\hline Difficulty breathing & 10 & 6 \\
\hline Irregular heartbeat & 8 & 4.8 \\
\hline Aggressiveness & 55 & 33.3 \\
\hline Nosebleeds & 4 & 2.4 \\
\hline Numbness or tingling in hands or feet's & 28 & 17 \\
\hline Don't know & 45 & 14.4 \\
\hline Complications & No of respondents $(n=165)$ & Percent \\
\hline Paralysis (stroke) & 84 & 51 \\
\hline Heart attack & 74 & 44.8 \\
\hline Eye problems & 9 & 5.5 \\
\hline Kidney Failure & 17 & 10.3 \\
\hline Don't know & 46 & 27.8 \\
\hline Risk factors & No of respondent $(n=165)$ & Percent \\
\hline \multicolumn{3}{|c|}{ Unhealthy habits (Smoking \& alcohol } \\
\hline consumption) & 30 & 18.2 \\
\hline Obesity & 25 & 15.2 \\
\hline Age & 10 & 6 \\
\hline Physical inactivity & 32 & 19.4 \\
\hline Genetics & 3 & 1.8 \\
\hline Over consumption of salt & 85 & 51.5 \\
\hline Stress & 58 & 35.2 \\
\hline Saturated fat intake & 53 & 32.1 \\
\hline Don't know & 25 & 15.1 \\
\hline Treatment & No of respondents(n=154) & Percent \\
\hline Medications & 113 & 73 \\
\hline Diet control & 85 & 54.8 \\
\hline Daily exercise & 49 & 31.6 \\
\hline Don't know & 7 & 4.5 \\
\hline lifestyle modifications & No of respondents(n=165) & Percent \\
\hline No & 8 & 4.8 \\
\hline
\end{tabular}


Original Article

\begin{tabular}{lll}
\hline Yes & 157 & 95.1 \\
\hline Changes & No of respondents(n=157) & Percent \\
\hline Food Habits & 118 & 75.2 \\
Quit unhealthy habits & 31 & 19.7 \\
Physical activity & 70 & 44.6 \\
Maintain healthy weight & 20 & 12.7 \\
Don't know & 7 & 4.5 \\
\hline Medicine consumption & No of respondents (n=165) & Percent \\
\hline When BP high & 21 & 12.7 \\
Whole life & 96 & 58.1 \\
Others & 5 & 3 \\
Don't know & 43 & 26 \\
\hline Prevention & Frequency & Percent \\
\hline Physical activity & 78 & 47.3 \\
Healthy weights & 12 & 7.3 \\
Quit smoking \& alcohol consumption & 28 & 17 \\
Less consumption of salt & 89 & 53.9 \\
Healthy foods & 55 & 33.3 \\
Don't know & 29 & 17.6 \\
\hline HTN \& smoking/alcohol & No of respondents (n=165) & Percent \\
\hline No & 31 & 18.8 \\
Yes & 134 & 81.2 \\
\hline
\end{tabular}

The above table shows that among the respondents only $54 \%$ (89) were able to define the hypertension as an elevated blood pressure, $3.6 \%$ as a rise in systolic blood pressure and $0.6 \%$ as a rise in diastolic blood pressure and only 34\% of respondents were able to recognize the normal range of blood pressure. Majority of respondents 51.5\% reported drowsiness or confusion as a major symptom of hypertension. $27.8 \%$ of respondents don't have knowledge on complication of hypertension. 51.5\% responded over consumption of salt as risk factors of hypertension.

Table 3: Distribution of respondents by level of knowledge

\begin{tabular}{lll}
\hline Category of knowledge & No of respondents & Percent \\
\hline Poor knowledge (<mean) & 79 & 47.9 \\
Good knowledge (>mean) & 86 & 52.1 \\
\hline
\end{tabular}

The table shows that the $47.9 \%$ of respondents have poor knowledge whereas $52.1 \%$ have good knowledge regarding hypertension. 
Attitude on hypertension

Table 4: Attitude of respondents about hypertension

\begin{tabular}{|c|c|c|c|c|c|}
\hline Questions & $\begin{array}{l}\text { Strongly } \\
\text { Agree }\end{array}$ & Agree & $\begin{array}{l}\text { Neutra } \\
\text { l }\end{array}$ & Disagree & $\begin{array}{l}\text { Strongly } \\
\text { disagree }\end{array}$ \\
\hline $\begin{array}{l}\text { Hypertension is closely associated with } \\
\text { individual's habit. }\end{array}$ & 27.9 & 27.3 & 23 & 14.5 & 7.3 \\
\hline $\begin{array}{l}\text { Hypertension } \\
\text { medications. }\end{array}$ & 46.1 & 42.4 & 9.7 & 1.8 & \\
\hline $\begin{array}{l}\text { Hypertensions cannot be treated } \\
\text { completely. }\end{array}$ & 19.4 & 26.7 & 19.4 & 29.7 & 4.8 \\
\hline $\begin{array}{l}\text { Hypertensive patients can skip their } \\
\text { medications when the blood pressure } \\
\text { slows down. }\end{array}$ & 13.3 & 22.4 & 10.9 & 35.2 & 18.2 \\
\hline $\begin{array}{l}\text { Hypertension can be prevented with } \\
\text { diet control and physical activity. }\end{array}$ & 39.4 & 43.1 & 14.5 & 3 & \\
\hline $\begin{array}{l}\text { Hypertensive people should quit } \\
\text { smoking. }\end{array}$ & 55.2 & 32.7 & 9.7 & 2.4 & \\
\hline $\begin{array}{l}\text { Hypertensive people should completely } \\
\text { avoid red meat. }\end{array}$ & 27.9 & 29.7 & 29.7 & 12.1 & 0.6 \\
\hline Hypertension is genetic disease. & 17 & 17 & 24.2 & 31.5 & 10.3 \\
\hline $\begin{array}{l}\text { Blood pressure should be checked on } \\
\text { Regular basis. }\end{array}$ & 63 & 30.3 & 5.5 & 1.2 & \\
\hline $\begin{array}{l}\text { Hypertension if untreated can result in } \\
\text { death. }\end{array}$ & 64.3 & 32.1 & 1.8 & 1.2 & 0.6 \\
\hline
\end{tabular}

The attitude of the participants on medications for controlling high blood pressure is found to be agreed by $46.1 \%$. $31.5 \%$ of respondents disagreed that hypertension is a genetic disease.

Table 5: Distribution of respondents by category of scoring on attitude based on attitude percentage

\begin{tabular}{lll}
\hline Category of attitude & No of respondents $(\mathbf{n}=165)$ & Percent \\
\hline Negative attitude $(<80)$ & 92 & 55.8 \\
Positive attitude $(>80)$ & 73 & 44.2 \\
\hline
\end{tabular}

The table on scoring of attitude shows that $55.8 \%$ of respondents had negative attitude whereas $44.2 \%$ had positive attitude relating hypertension. 
Preventive practices section

Table 6: Distribution of respondents by preventive practices

\begin{tabular}{lll}
\hline Daily exercise & No of respondents $(\mathbf{n}=\mathbf{1 6 5})$ & Percent \\
\hline Yes & 75 & 45.5 \\
No & 90 & 54.5 \\
\hline Time of exercise & No of respondents $(\mathbf{n}=\mathbf{7 5})$ & Percent \\
\hline less than 30 minutes & 23 & 30.7 \\
more than 30 minutes & 22 & 29.3 \\
1hr & 12 & 16 \\
more than 1 hr & 18 & 24 \\
\hline Consumption of fresh & No of respondents & Percent \\
vegetables and fruits & (n=165) & 52.7 \\
\hline Regular & 87 & 40 \\
3-4 days in a week & 66 & 7.3 \\
Occasionally & 12 & Percent \\
\hline Saturated fat intake & No of respondents & 6.1 \\
\hline Regular & 10 & 82.4 \\
Occasionally & 136 & 11.5 \\
Never & 19 & Percent \\
\hline Unhealthy habits & No of respondents & 72.1 \\
\hline Smoking & 49 & 47.1 \\
Alcohol consumption & 32 & am
\end{tabular}

The above table shows that $45.5 \%$ had habit of exercising daily among which majority of respondent's exercise for less than 30 minutes. Similarly, 52.7\% regularly consume fresh vegetables and fruits and only 6.1\% consume saturated fat on regular basis. Also $72.1 \%$ and $47.1 \%$ were found to be smokers and alcoholics.

\section{DISCUSSION:}

In this study the definition of hypertension as an elevated blood pressure had been identified by $54 \%$ of respondents. Also only 34\% of respondents correctly identified the normal range of blood pressure whereas $61.8 \%$ did not know the normal blood pressure which is similar to another study of Oliveria ${ }^{(6)}$ et.al where $30 \%$ of patients identified normal BP. In this study, $40.6 \%$ and $51.5 \%$ of samples responded severe headache and drowsiness or confusion as main symptoms of hypertension followed by 33.3\% aggressiveness similar to Iyalomhe ${ }^{(7)}$ and Sarah I. Iyalomhe (40\% indicate headache as a prominent symptom) The risks factors of hypertension had been identified as a over consumption of salt (51.5\%), stress (35.2\%), saturated fat intake (32.1\%), and obesity 
(15.2\%) in this study. The average knowledge score of respondents was 12.9 out of maximum 41 score. The mean percent knowledge score was 31.5\% with maximum knowledge percent of 88\% and minimum of $0 \%$. In this study, $47.9 \%$ had a poor knowledge and $52.1 \%$ had a good knowledge on hypertension. The overall knowledge level of respondents was found to be good but the knowledge on specific portions of hypertension were lacking such as normal value of blood pressure and meaning of high blood pressure.

The attitude score of $44.2 \%$ respondents on hypertension found to be positive. The average attitude score was 38.8 out of maximum 50 score. The maximum attitude score was $98 \%$ and minimum $54 \%$ with an average of $77.58 \%$. The attitude of the participants on medications for controlling high blood pressure is found to be agreed by $46.1 \%$. In contrast to this another study by Shakya ${ }^{(8)}$ et.al among hospital staff in Sahid Gangalal hospital showed that 72\% had positive attitude towards medication for hypertension. In another similar kind of study by $\operatorname{Pramar}^{(9)}$ et.al $72 \%$ respondents agreed on regular medications for hypertension control.

In this study $45.5 \%$ of respondents were found to be engaged in a daily exercise with the highest proportion i.e. 30.7\% exercising for less than half hour. The considerable number of participants $54.5 \%$ was found to be not having the practice of exercise. In this study $72.1 \%$ of respondents were reported to be smokers and $47.1 \%$ were drinking alcohol. This is comparable to the Mlunde Linda's ${ }^{(10)}$ cross-sectional study where $52.35 \%$ reported to be doing physical exercise regularly, 9.54\% were reported being smokers and $29.26 \%$ as drinking alcohol.

\section{CONCLUSION:}

The study aimed to assess KAP on hypertension showed that more than half (52.1\%) of respondents had good knowledge although there was a lack of knowledge on specific factors regarding risk factors, symptoms, complications, treatment and prevention of hypertension. Majority of respondents i.e. 55.8\% had a negative attitude towards hypertension. Despite of the good knowledge and positive attitude large number of participants had poor preventive practice so they are predisposed to the risk factors of high blood pressure. 


\section{RECOMMENDATIONS:}

Mass awareness and health promotion programs should be organised by the health personnel and concerned authorities in order to increase the knowledge among people regarding complications, symptoms and normal value of blood pressure. The awareness program should focus the people with lower educational status and people of older age. Minimization of saturated fat intake, promotion of fruits and vegetables consumption including motivation for regular exercise and quitting unhealthy habits should be promoted as a key healthy life free from hypertension. The behaviour change communication program should be launched so as to improve the preventive practices of people.

\section{REFERENCES}

1. Grove C LN. Disorders of the cardiovascular system. Harrison's principles of internal medicine. 2005:230.

2. Omran, R A. The Epidemiologic Transition: A Theory of the Epidemiology of Population Change. Population Health and Health Policy. 2005 Dec;83(4):731-57.

3. Burt VL CJ, Higgins SM et al. Trends in the prevalence, awareness, treatment, and control of hypertension in the adult US population. Journal of Hypertension. 1960;26(1):60-9.

4. WHO. Reducing risks, promoting healthy life. Geneva: World health organization2006.

5. Aubert l, Aubert, Pascal B, Jean GP, Anne R, Bernard W, Fred P. Knowledge, attitudes and practices on Hypertension in a country epidemiological transition. Hypertension, Journal of American heart association. 1998;31:1136-45.

6. Oliveria SA, Chen RS, McCarthy BD, Davis CC, PharmD, Hill MN. Hypertension Knowledge, Awareness, and Attitudes in a Hypertensive Population. Journal of Internal Medicine. 2005 Mar;20(3):219-25.

7. Iyalomhe GBS, Iyalomhe SI. Hypertension-related knowledge, attitudes and life-style practices among hypertensive patients in a sub-urban Nigerian community. Journal of Public Health and Epidemiology. July 2010;2(4): 71-7.

8. Shakya S, Bhattarai J, Rawal K, Kunwar A, Shakya Y, Sharma D. Socio-economic Analysis and the Study of Prevalence, Awareness, Treatment, Control and Risk Factors of Hypertension in Hospital Staff. Nepalese Heart Journal. 2010;7(1).

9. Parmar P, Rathod GB, Rathod S, Goyal R, Aggarwal S, Parikh A. Study of knowledge, attitude and practice of general population of Gandhinagar towards hypertension. International Journal of Current microbiology and applied Sciences. 2014;3(8):680-5.

10. Linda M. Knowledge, Attitude and Practices Towards Risk Factors for Hypertension in Kinondoni Municipality, Dar es Salaam. DMSJ. 2006/2007 14(2). 